\title{
Effective Design and Implementation of B.Tech (CSE) Curriculum with Industry Tie-ups
}

\author{
Dr.S.Shashi Anand ${ }^{1}$, Dr.A.Francis Saviour Devaraj ${ }^{2}$, Dr.R.Kanniga Devi ${ }^{3}$, \\ Dr.C.Bala Subramanian ${ }^{4}$, Mr.R.Raja Subramanian ${ }^{5}$, Mr.P.Nagaraj ${ }^{6}$
}

\author{
${ }^{1}$ shasi.sridharan@aiht.ac.in \\ ${ }^{2}$ francis@klu.ac.in \\ ${ }^{3}$ r.kannigadevi@klu.ac.in \\ ${ }^{4}$ c.balasubramanian@klu.ac.in \\ ${ }^{5}$ rajasubramanian.r@klu.ac.in \\ ${ }^{6}$ nagaraj.p@klu.ac.in
}

${ }^{1}$ Vice President, Kalasalingam Academy of Research and Education, Anandnagar, Krishnankoil, Virudhunagar Dt,India

${ }^{2}$ Professor, Department of Computer Science and Engineering, School of Computing, Kalasalingam Academy of Research and Education, Anandnagar, Krishnankoil, Virudhunagar Dt,India

${ }^{3}$ Associate Professor, Department of Computer Science and Engineering, School of Computing, Kalasalingam Academy of Research and Education, Anandnagar, Krishnankoil, Virudhunagar Dt,India

${ }^{4}$ Assistant Professor, Department of Computer Science and Engineering, School of Computing, Kalasalingam Academy of Research and Education, Anandnagar, Krishnankoil, Virudhunagar Dt,India

${ }^{5}$ Assistant Professor, Department of Computer Science and Engineering, School of Computing, Kalasalingam Academy of Research and Education, Anandnagar, Krishnankoil, Virudhunagar Dt,India

${ }^{6}$ Assistant Professor, Department of Computer Science and Engineering, School of Computing, Kalasalingam Academy of Research and Education, Anandnagar, Krishnankoil, Virudhunagar Dt,India

latest trends and technologies for faculties and students. The project-based and practice-based learning groom up the research skills of the students. A study is conducted with a stratified sampling on 400 students of the University in 3 batches, composing students trained through institute-only curriculum and $I^{2}$ curriculum in equal strands. The skills of the students are evaluated through society oriented problems, reflecting the students' ability in applying the engineering knowledge on real world problems. Empirical evaluations are conducted on the outcomes of the students on grounds of internship offers received from industries, papers published and patents filled on societal problems. The evaluations reveal that the design thinking, selflearning ability, state-of-the-art knowledge of the $I^{2}$ curriculum-oriented students are $59.27 \%$ ahead from the former case of students. Being a continuously improving model, it is obvious that the student outcomes and the societal growth will grow in par with the technology development. In addition, the institution has collaboration with SAP, through which students are trained to secure international certification and hence boost the chances of 
getting jobs. At the outset, it is believed that the InstituteIndustry collaborations will help in making the graduates readily employable and aid in societal development.

Keywords: Industry-Institute collaboration, B.Tech(CSE) curriculum, IBM ICE-KARE, SAP, Employability, Societal development

\section{Introduction}

In recent decades, the term 'Globalization' emerged and it involves economic interdependencies among the countries considering the whole world as one village. Globalization describes the increasing trend towards the interconnectedness of business and the people across the world to enhance the global economic and political integration. Nowadays, both engineering education and firms have been impacted by globalization. Global competition is the service offered by the companies competing to serve international customers. Globalization is mandatory for students in higher education, as the education systems are now preparing the students to acquire global multicultural skills and competencies to succeed in this globalized world (Inzelt et al., 2004). Thus, globalization motivates the collaboration between institutions and industries. Indian Industry plays a major role in placing India on the global map and makes it a knowledge based economy.

Industry-Institute Collaboration is a major factor that enables the Indian Education sector to flourish in the Global Knowledge Index. Industry-Institute Collaboration is the prime factor to build skilled India. Competition between industries has become stiff due to the advent of globalization and the opening up of the Indian economy to the outside world. Industries are hungry for ideas and talents, so they drive towards engineering institutions (Bhattacharya et al., 2007). On the other hand, institutes are eyeing the multinational companies to prepare their students for jobs, by exposing them to newer engineering technologies and methodologies. These objectives can be achieved well by maintaining a symbiotic relationship among the companies and the universities. Industries and institutes collaboration have been in practice for many years; however, the rise of a globalization in economy has reinforced the need for deliberate collaborations. This interaction provides a platform for educational institutions to provide an opportunity for their students to make them aware of industry expectations regarding the requirement of skill sets. Thus, the students could be aware of the lacunae in their skills and can upgrade them. Even though we have abundant manpower availability in India, well-equipped manpower with employability skills is very much essential.

Higher engineering education serves as key boosters of creation, innovation, and competitiveness in the global economy that meet the needs of the society. Higher engineering education aims to fulfill the development and socio-culture needs of a country. In the globalization world with a knowledge-based economy, a prerequisite for shaping the future society needs knowledgeable and qualified graduates with moral and ethical values that are developed by higher engineering educational institutions. Institutions provide education, skill-oriented training, and a research environment with innovations having high economic value and applications.

Due to the advent of globalization, the industry has to compete in the global market by improving its quality and efficiency. Besides, the students of engineering institutions lag in industrial experience as they are taught only with their particular skills and knowledge. There occurs a high contradiction between industrial practice and academic study. This leads to the development of Industry-Institute Collaboration. Industry-Institute Collaboration also called Academic level collaboration is needed to minimize the gap between academic offerings provided by the institutions and industry expectations from the institutions. This active involvement of industries in the educational process facilitates designing projects, curriculum improvement, seminars, internships, and summer training for students, broad exposure of the industrial atmosphere to the students, and providing employment opportunities for students. Industry-Institute Collaboration is considered as the main criteria for the appraisal of institutions. Consequently, this Industry-Institute collaboration fabricates the most inspiring technological innovations.

Majority of the United States (US) industries depend on the academic universities to bring creativity and innovations in their work. Some institutions face a big challenge in establishing collaborations with industries particularly those in Australia, South America, and Asia. In India, most of the industries rely on their own research group rather than on the academic institutions. (Kawday 2019).

Academic-Industry Collaboration in India is rated as 4.7 out of 10. This is because, initially India has taken only a few steps to develop this collaboration as they lack clear policy and coordination to strengthen this links. There is a need to develop strong and robust Industry-Institute Collaboration by which knowledge gets transferred from the institute lab to the market. Nowadays, some industries 
have realized the importance of such Industry-Institute linkages and engage themselves in research projects along with the academic universities. Some of the top AcademicIndustry Collaborations followed in India are IISc (Bengaluru) with Wipro to develop robotics, 5G, Metal 3D printing and autonomous systems, IIT (Kharagpur) join hands with Wipro in the areas of 5G, Samsung India with IIT (Guwahati) in the areas of Machine Learning, IoT, and Artificial Intelligence, IIT (Madras) join hands with Sterlite Technologies in the areas of $5 \mathrm{G}$ applications, IIT (Hyderabad) with four Japanese institutions for Disaster Resilience, IIT (Kanpur) with Tech Mahindra in the areas of Cyber Security, IIT (Delhi) with (ISRO) Indian Space Research Organization, which set up a space technology center in their university premises, IIT (Roorkee) with Apollo Tubes Limited for steel pipes manufacturing, and Tata Motors with IIT (Bombay), develop an electric race car (EVoK) (https://timesofindia.indiatimes.com)

National Education Policy 2020 (NEP 2020) implies a huge milestone for education system in India by transforming India as 'vibrant knowledge hub'. This policy insists that engineers should excel in rapid innovative technological paradigm globally. Besides, this policy emphasizes that weak collaborations will result in poor research and development. Specialists from academic institutions should join hands with the industry experts in solving complex scientific problems, making researchers aware of the current national research issues and providing useful products to the society. Besides, this collaboration will help to sustain high talents in the country, as there is no need for the students to move out to pursue education. Hence, an effective Industry-Institute Collaboration will prepare its young population for the global economy (https://www.mhrd.gov.in/sites/upload_files/mhrd/files/ NEP_Final_English_0.pdf).

Through Industry-Institute Collaboration, the universities upgrade their student's knowledge with the recent innovations and technologies that are needed for the industry from the base itself. Recruitment pattern of the industry changes from recruitment-training model to recruitment-work model. Recruitment-training model involves recruiting the students from universities and training them for a particular time period. In contrast, the Recruitment-work model gives the students direct employment as they are already aware of the new innovative methods and technologies. Hence, this paper focuses on Industry-Institute collaboration between IBM ICE and Kalasalingam Academy of Research and Education and also the collaboration between SAP and
Kalasalingam Academy of Research and Education and the outcome of collaboration.

\section{Literature Review}

The term collaboration effort signifies "cooperating to accomplish a typical objective" and the coordinated effort can be at various levels, that is, at a person, bunch organizations, segment, and public levels while its structures might be 'intra-structures' or 'inter structures' (Inzelt et al., 2004).

A base foundation for the prerequisites of enterprises ought to be set up for the powerful institutional support in tests and examinations which lead to increment in modern consultancy works. As the Institute-Industry Collaboration includes a different arrangement of exercises, it is fundamental that rules, which establish an institutional approach, ought to be created for proceeding and beneficial connections between the organization and the industry (Calvert, J et al., 2003).

Faculty and students should be urged to participate in proper external associations with the ventures. Such outside exercises can furnish the individual faculty with experience and information that are significant to educate, investigate, and assist understudies with increasing more extravagant instructive chances and encounters. The Institutional executives should build up fitting standards and guarantee the presence of an open climate with the expectation of complimentary trade of thoughts (http://www.ucop.edu/ott/genresources/unindrel.html).

As Institute-Industry Collaboration effort includes a various arrangement of exercises and results in an assortment of yields, no single measure can catch the full scope of such coordinated effort, and henceforth the achievement of Institute-Industry Collaboration relies upon the different boundaries that are utilized for surveying the adequacy of Institute-Industry Coordinated effort. The parameter includes general collaboration, academic level collaboration, institutional support type collaboration, service type collaboration, cooperative type collaboration, and student-level collaboration (Bhattacharya et al., 2007).

Linkages of the industry with college and logical exploration foundations are given exceptional consideration. The arrangement archive has called for the formation of innovation move associations as partner associations of colleges and public research centers to encourage the movement of ability produced. The arrangement record expresses that industry will be urged to 
monetarily receive or uphold instructive and research foundations, finance courses important to them, make teacher seats, and so on so S\&T attempts can be coordinated towards substantial mechanical objectives through cooperation with establishments. (Sujit Bhattacharya et al., 2007)

The "Triple Helix" which alludes to the various corresponding connections among institutional areas (government, industry, and scholastic) at various focuses in the information capitalization measure (for example Making of information, agreement, and advancement spaces) and hence the "Triple Helix" is a winding model of development that catches numerous complementary connections at various focuses during the time spent information capitalization (De'Este et al., 2007).

The collaboration underscores the significance of college in the advancement framework and the part of the government as a controller and facilitator of R\&D, development action, and association. The three strands of the helix are the scholarly community, industry, and government, and the model permits us to consider the various types of connections between the three strands of collaboration. (Annamaria Inzelt, 2004)

The employees should be urged to participate in suitable external associations with the ventures. Such external exercises can furnish the individual employee with experience and information significant to instruct and investigate and assist understudies with increasing more extravagant instructive chances and encounters. The Institutional heads have to set up suitable standards and to guarantee the presence of an open climate with the expectation of complimentary trade of thoughts for collaboration (www.ucop.edu).

A base establishment for the requirements of undertakings should be set up for the effective institutional collaboration in tests and examinations which lead to the expansion of information or to expanded viability in educating. As the Industry-Institute Collaboration includes a different arrangement of exercises and results in an assortment of results, it is vital that rules, which comprise institutional approach, should be created for proceeding and beneficial connections between the college/foundation and the industry (J. Calvert et al., 2003).

To infer the full advantages of Collaboration, it is important to recognize and eliminate the obstructions/inhibitors for Collaboration: Identify committed people on either side and enable them; empower likely accomplices to speak with one another; agreement acknowledgment for synergistic work; set up institutional instruments for advancing cooperation; distinguish community organization as a key goal (A.N. Parameswaran et al.,2009).

\section{Implementation of Industry- Institute collaboration of KARE}

\subsection{Implementation of Industry- Institute collaboration between KARE-IBM}

The advancement of technology has created a vast demand and equal challenges in devising applications for smart execution of voluminous tasks. Ever since the computers invaded the civilized life and digital era forging ahead in rapid pace, fields like medical, production, banking and agriculture have turned towards these advancements. Need for such applications lies on smart performance and saving of time among people and corresponding fields. Consequent to this, there has been a great demand and urge for technologists, chiefly from computer arena and information technology arenas. These two streams of engineering and technology provides vast scope for employment, updated concepts to face the challenges in the field, apart from assuring life time job opportunities. The core programs in this field are tailormade to match the expectations and requirements of the digital industries. Necessary skills and technological knowledge are duly incorporated in the study programs of computer engineering. Computer Engineering program offers widespread areas of learning to equip and train the students with regard to their interest, involvement and efficiency. All the concepts which are exposed in this Computer Engineering program prepares the student community to transform themselves as technologists for industries. Research thrust is also included in the program which will elevate the students to the global level. This program has specialties on learning tasks by making them apply knowledge, skills \& fundamental principles to solve real world problems. This program further envisages a keen awareness among the students on technological perceptions to solve issues related to global and social contexts.

The International Business Machines Corporation (IBM), with its headquarters in Armonk, New York , United States, is an American multinational technology and consulting firm.In areas ranging from mainframe computers to nanotechnology, IBM produces and markets computer hardware and software, and provides infrastructure, hosting and consulting services. 
The "IBM's Initiative towards a New Education Paradigm", is an offspring for an advanced learning of specialization programs in computer engineering under B. Tech / PG Computer Science / IT. These programs are designed to engulf the gap between the Industry and Academia. Keeping the motif of IBM's initiative, Kalaslaingam Academy of Research and Education (KARE) has tied up with IBM to offer the same programs.As such, KARE and IBM have collaborated for offering Bachelor of Technology (B.Tech) Computer Science and Engineering (CSE) Programs with IBM Certification in four streams. The four streams as follows,

\section{Artificial Intelligence and Machine Learning (AIML) \\ 2. Cyber Security \& Forensics \\ 3. Data Analytics \\ 4. Internet of Things and Smart City}

Courses and mainstream programs on Technology are offered over the IBM Innovation Center for Education (ICE). The programmes thus offered are industry-aligned, with a state-of-the-art delivery system that helps students to learn and develop industry-oriented skills, and the courseware has been revamped from the ground up.

This platform offers an online forum for students and faculty to engage with Subject Matter Experts (SMEs) and mentors in the industry.This aspect shows that the partnership of the industry is a specific and integral part of the programme.Regular Faculty-SME interaction, as one of the major ingredients of this model, is another hallmark of this curriculum.Students are exposed to hands-on learning experiences, industry experts' guest seminars, online labs, on and off campus technical activities.Further, the program is highly user-friendly with enjoyable, efficient and stimulating learning while infusing the professionals of the future with profound abilities. Students will also get exposure to the mainstream tools used in industry in the AIML, Cloud Computing \& Virtualization, Cyber Security $\&$ Forensic, Data Analytics and Internet of things domain. All these mould and make the students gain and develop team work experience of professional skills for IT Industry

Students become eligible for an IBM digital badge upon successful completion of the programme.The IBM ICE Digital Badges are a new online standard for the evaluation, identification and verification of skills gained during the learning process.Each badge includes checked metadata detailing the learners' credentials and equips them with the rigorous process required for industries to earn.On social and technical networking sites and in one's digital signature, a Digital Badge may be posted.IBM ICE Digital Badges provide valuable advantages for students, such as

- Credentials in Digital version

- Recognition of abilities associated with industry

- Globalrecognition

- For fine deployment of badges, free access to a badge wallet - Safe and verifiable storage and disclosure of
personal credentials

\subsubsection{B.Tech (CSE) specialization with Artificial Intelligence and Machine Learning}

The chief objective of the program is to analyse and interpret data patterns and structures to allow outside human involvement to understand, reason, and make decisions. Emphasis is laid on the inculcating a mastery of specific software tools or programming environments. a 'Hands-on' approach for understanding, as well as a challenging avenue for exploration and creativity are infused through assigned projects.

By learning the concepts, the Badge earner will acquire a sound knowledge of prediction techniques and machine learning concepts. All through the program tenure, the student will have earned an understanding on machine learning model for simulation and analysis. Moreover, the student will be capable of exploring the current scope, potential, limitations, and implications of intelligent systems.

\subsubsection{B.Tech (CSE) specialization with Cyber Security \& Forensics}

Cyber Security \& Forensics is a branch of digital forensic science that is primarily applied to cyber space and digital storage media for legal evidence.The digital age has been promoting and witnessing an exponential growth in the need for cyber experts. The factbehind this movement is that nations have turned towards the booming internet applications, especially in the fields of e-commerce, ebanking, e-governance and the social media.

The major objective of this program is to train and equip the student for an exciting career in the domain between government cyber organizations and public sectors such as DRDO, ISRO or private firms which adopt IT security. Students who pursue this program have excellent job opportunities in the form of Cyber Forensics Solutions Architect / Planning \& Expansion Specialist / Administrator / Tech Consultant Examiner / Engineer / Malware Analyst / Expert at antivirus firms / Cyber Security Architect / Information Security Analyst/ Network Security Analyst / Computer and Information System Manager etc.

\subsubsection{B.Tech (CSE) specialization with Data Analytics}

This program is devised with an objective make the students learn how to identify, analyze and solve business problems using Analytics in the specific areas of Business Analytics, Data Warehouse \& Data Mining, Business Intelligence, Social, Mobile \& Web Analytics.

Through this program, the Badge earner is assured of acquiring good critical thinking, visual modeling and analytical skills. Thus, there is every possibility to apply descriptive, predictive, social, web \& mobile analytics thereby meeting the business situations with appropriate solutions. The student will be stuffed with sufficient knowledge on Process Mapping, Risk Assessment, Data 
Warehouse and Multidimensional Modelling, and will also learn the applications of several analytical tools

\subsubsection{B.Tech (CSE) specialization with Internet of Things and Smart City}

The purpose of the programme is to encourage students to explore the interconnection and integration of the physical world and cyber space. The Internet of Things is a term given to the attempt to link objects to the internet and also to each other-to allow individuals and objects to evaluate data from different sources in real time and to take the required steps in an intelligent way.This will help students gain the required knowledge to create IoT systems and to use cloud resources to process and store IoT devicegenerated data.The goal of this stream is to establish awareness and critical understanding of the fundamental concepts of cloud computing and IoT systems, as well as the business and commercial implications of technological developments in this field.

Thorough awareness of IoT products, programmes, networks and infrastructure will be gained by the badge earner. Students also have a good ability to design sensor networks and IoT network planning. Also, students will gain sufficient knowledge on establish and deploy the middleware and NoSQL database to collect the data from the IoT devices., and will also learn the usage of several analytical tools

\subsubsection{Courseware and Program Access On completion of the program}

1. DEGREE will be awarded by Kalasalingam Academy of Research and Education - B.Tech Computer Science.

2. IBM will provide course relevant project works to students with help of IT industry/ partners.

3. Curriculum - The Course Curriculum will be designed and implemented by the academic team of Kalasalingam Academy of Research and Education in association with IBM. This would be an extensive and in depth work shop to help us blend the content into our curriculum.

4. Joint Conferences -IBM will facilitate Kalasalingam Academy of Research and Education in terms of guest speakers, workshops and other technological conference related matters.

\subsubsection{IBM industry-based curriculum and implementation}

The curriculum helps students deal with rapid technological shifts, making them better suited for the IT industry 's needs.They will be exposed to up-to - date curriculum and training related to technology / industry adapted by the faculty.

Program courses of each semester are industryoriented, matching the ongoing advancements in digital industries. The curricula will be designed by including concepts on Foundation, Core \& Advanced subjects. IT industry experience with an emphasis on laboratories and hands-on training will be tagged with significant and important significance. The courses will be quite anew, offering the latest concepts and be contemporaneous meeting the ever-changing demands of the industries.

\subsubsection{Student, Faculty Training}

The curriculum has a groundbreaking course delivery approach that requires the use of both one-to-one format between the faculty and the student. There will be a continuous collaborative online learning between SMEs in the industry, faculty teams and students. There will be frequent On-campus SME workshops, Webinars, immersive online learning with classroom sessions, Discussion Boards, Business Ventures, Industry Mentors, Gurukool. To kindle the interest and competitiveness among the learners there will beSummer Enthusiasm session on campus, in addition to the competition for posters and technical articles.

\section{Train The Trainer(T3)}

The program of IBM ICE consists of Academic workshops like T3 (Train The Trainer) workshops and SME (Subject Matter Expert) guest lectures. There will be exclusive T3 workshops for the internal faculty members enabling them to communicate course content in an effective manner. The T3 workshops will be of 3-5 days duration depending on the subject at hand.

\section{Subject Matter Expert (SME)}

SME GUEST LECTURES are conducted by SMEs for of 4-6 hours duration. Theselectures are designed pertaining to the subject they undergo from time to time. Such lectures will surely provide understanding the complexity of the subject. The Guest Lectures also cover the existing industry trends and the latest developments in the respective subject.

\section{Gurukool}

This is a knowledge sharing meet participated by the students of similar institutions undertaking the programs under IBM ICE. The meet will be monitored by the personnel of IBM at a specified locale. This will be conducted once in 4 years in which the students will get opportunities to meet peer students and exchange the concepts and ideas in a cordial and funny manner.

\section{IBM ICE Inter University Competition}

IBM ICE Inter-University Competition is conducted to assess the competency of the students with their counterparts from other Universities. Coordinated by IBM, this event was conducted for the First Year Computer Engineering students in which 230 students participated.

\section{IBM ICE day}


IBM ICE Day is an ideal platform for students to showcase the talent along multiple dimensions. 3 main events are being conducted during theIBM ICE day :

1. Hackathon: This comprises a high-level conceptual understanding of a problem statement and its proposed design solution.

2. Paper presentation: This is the first step towards inculcating a research attitude among undergraduate students.

3. Poster presentation: It consists of the concise depiction of a specified domain. Delegates from IBM along with faculty members from the Computer Engineering Department, KARE evaluated ideas presented by the students in these three different competitions.

\section{IBM Project:}

As a part of MoU, IBM offer real time industry projects for our students from second year onwards. The experts from IBM guiding the students to complete the projects. After completion of projects they rank the projects based on industrial satisfaction and they provide case prize and also appreciation certificates. These real time projects help our students to know about the industry atmosphere while studying the course itself.

7. Evaluation Methods:

All the IBM courses have been evaluated based on the following criteria:

a. Experiment based evaluation

For a course, individual student is evaluated for his/her ability to design and conduct experiments and report the findings. More weightage is given for the analysis of the result.

b. Model design/development

Individual student is involved for design and development of the model. Model making involves some engineering component (in terms of analysis or its functioning).

c. Evaluation by industry persons

IBM resource persons are invited to offer a real time industry problem and evaluate the students' performance. It also includes interviews by the industry persons.

These evaluation metrics help our students to understand the course in a deep manner and also it provides more practical knowledge about the course.

\subsection{Implementation of Industry- Institute collaboration between KARE-SAP}

SAP certification is the most popular certification in the information technology (IT) world. All over the world, SAP has created a huge buzz among IT professionals. Directly or indirectly, it has put millions of people in employment around the world. SAP certified consultants will benefit from special recognition from their employer.

SAP offers various modules to help companies grow their businesses. SAP-ABAP (Advanced Business Application Programming) is one of those modules, which is used to develop a corporate application for large businesses and financial institutions on the SAP platform.

Kalaslaingam Academy of Research and Education (KARE) has tie up with SAP to offer the same programs for the benefits of our students.

\section{Comparative Analysis on Student Records}

An analysis on the student records is carried out with a stratified sampling of 400 students in 3 batches. The stratification is done to narrow down the equity in the number of students under $I^{2}$ curriculum (IBM Students) and the number of students under normal curriculum (non-IBM students), in all comparative grounds. The ability of the students in self learning, design thinking and project building are evaluated in various criteria. Self learning encompasses the interests of the students in studying stateof-the-art technologies, programming languages, among others. Self learning of the students can be subjected by an initial evaluation on the number of certifications done by the students in online courses including NPTEL, Coursera, Udemy, etc. The willingness to learn by self will only be inculcated through the interest created onto the students. This interest comes through the higher level knowledge sharing between the teachers and students in a studentcentric learning environment.

Higher level knowledge sharing can be experienced only when the knowledge provider is up-to-date with the state-of-the-art knowledge in subject areas of his/her interest. This update comes by the similar self learning in teachers and also through professional development activities. Teachers/ knowledge providers being experienced in industries are considered in-line with technology. To make a similar effect among all the teachers in the academic environment, programmes such as T3 training are engaged between the industry-IBM in KARE and the teachers. With an improved teaching experience and $I^{2}$ curriculum, necessary transformation occurs in student knowledge. This transformation can be visualized in various aspects. 


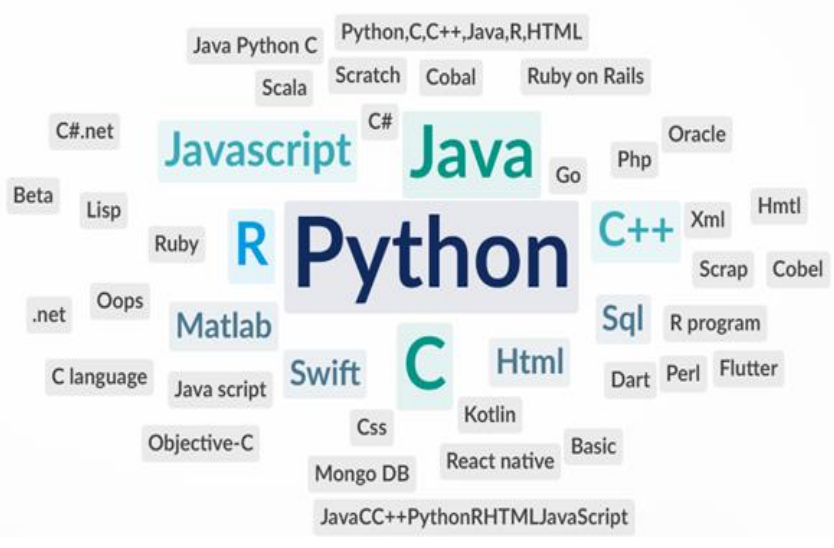

Fig. 1. Word Cloud on familiar languages of IBM Students

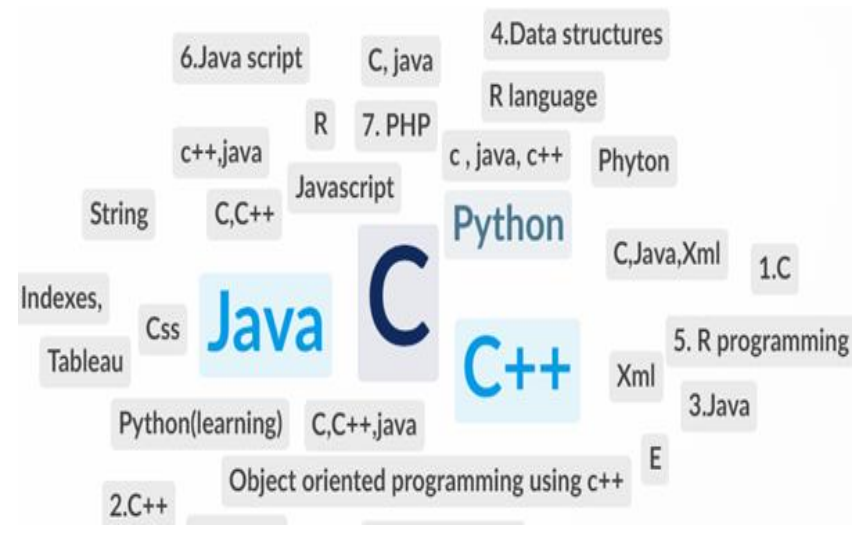

Fig. 2. Word Cloud on familiar languages of non-IBM students

A word cloud representation on the familiar programming languages of the students is constructed with the two groups under study. The survey is publicly shared to the students and 135 and 112 responses are obtained from IBM and non-IBM students. The visualization of the survey is depicted in Fig. 1 and Fig. 2 respectively for IBM and non-IBM student groups. It is obvious that there is a transformation in the most familiar language from $\mathrm{C}$ in the non-IBM group to Python in the IBM group. In addition, many industry specific tools are enumerated by the IBM students relative to the non-IBM group. Programming strength being the core-entity for project/ product development, this study shows the significant difference between the two groups. The industry oriented learners exhibit much higher levels of proficiency in programming paradigms.

The design thinking of the students can be calibrated by the real time problem solving ability in the students. Online platforms including Hackerrank, Project-Euler are primary grounds to showcase the problem solving ability. Among others, hackerrank forces the developers to leverage on their programming and technical skills to solve dynamic problems. Hence a study on the set of 56 active students composing IBM and non-IBM groups. The students are involved in problem solving in various languages including Python, Java, among others. Fig. 3 depicts the comparative analysis on the cumulative points of the students across various levels of problem solving at hackerrank platform [14]. It is comprehended that the number of students as well as the points are sufficiently large in IBM group rather than in non-IBM group. This is because of the influence of industry oriented curriculum inculcating higher levels programming languages and tools. The curriculum also encompasses problem solving as the main component in its pedagogy.

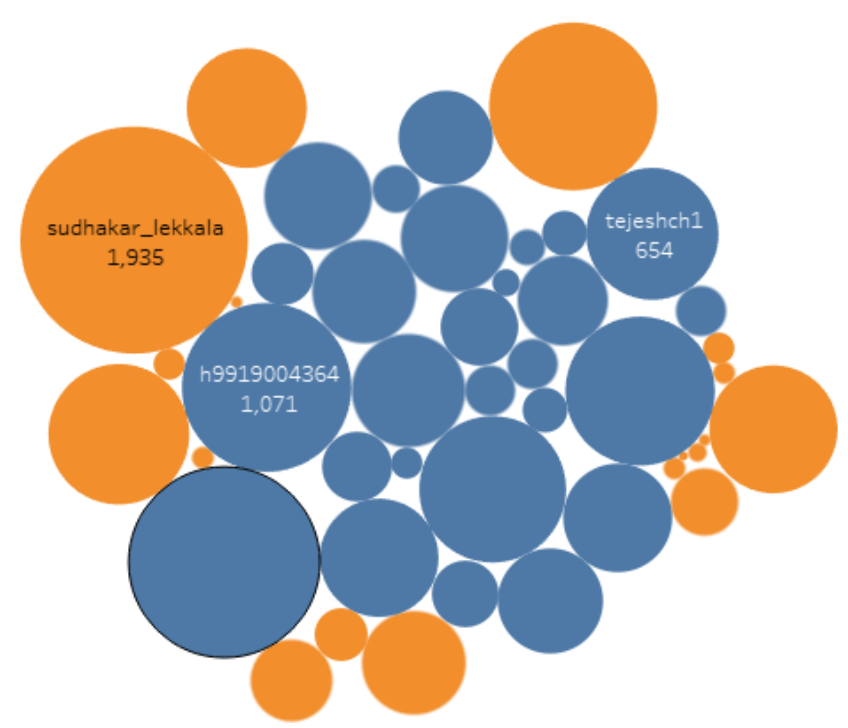

Fig. 3. Comparison of the problem solving knowledge of IBM and non-IBM students in Hackerrank platform

Comprehending and mastering the self learning and design thinking abilities, those students who involve their skills into project/ product development are considered to be converged in their Engineering study. In student-centric learning practiced in $I^{2}$ curriculum compose course-level projects, in addition to community service projects and major projects. The student projects are usually clustered based on the project constraints, viz. Economic, Environmental, Social, Ethical, Health and Safety, Manufacturability, Sustainability. The course level projects and mini-projects successfully completed by 200 students are taken into consideration. 100 students each from IBM non-IBM group are composed in the study. Fig. 4 depicts the number of students completing projects under various constraints. 


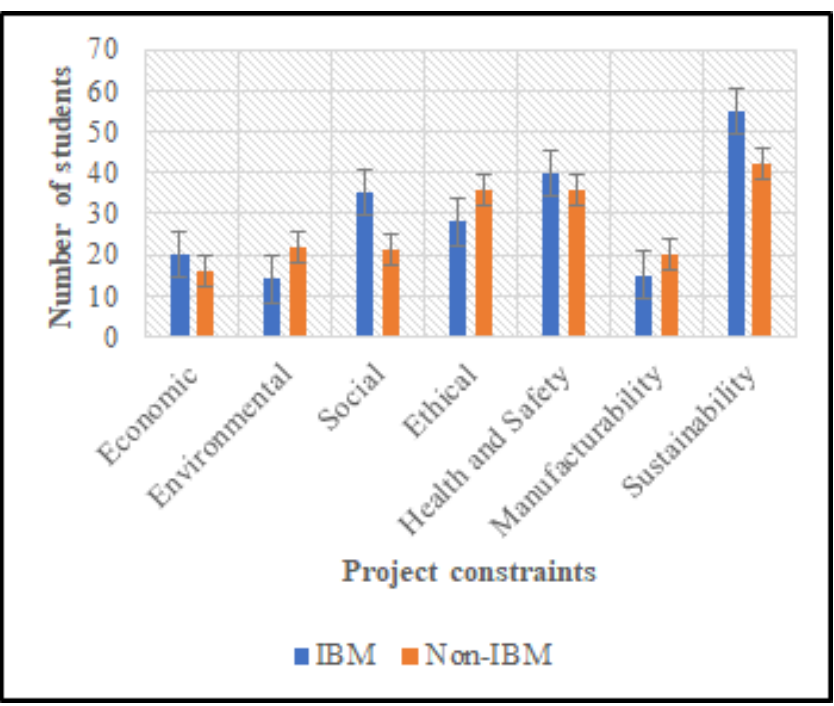

Fig. 4. Comparison on the number of projects done by IBM and non-IBM students with respect to the project constraints

It is evident that maximum projects from IBM and nonIBM groups surround sustainability. The number of students is comparatively higher in IBM group in Social and Health \& Safety project strands. Whilst the non-IBM students have limited concentration on social projects. There is a smaller number of economic and manufacturability types among both groups. These two are interrelated, and are evidenced when inter-departmental projects are executed. To narrow down, the IBM groups have started applying their design thinking ability in social/ community problems. Engineering solutions for societal problems are vital requirements for developing countries. The IBM group of students are aligned towards such development projects more than the later ones.

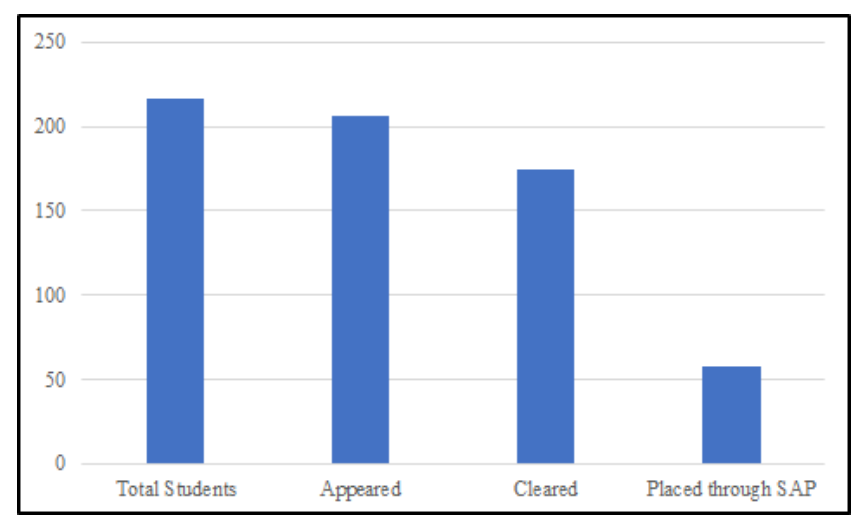

Fig. 5. Effect of SAP on Student Placements

In addition students' participation in industrial workshops and training including SAP, reflect in their placements. The Effect of SAP certification on placements is depicted in Fig. 5. It is evident that the maximum percentage of students clear the exam and comparable numbers make use of the same for placements. From the study, the knowledge acquisition on the basis of self learning and design thinking in students is quantified through their programming ability, certifications, design thinking ability reflected through hackerrank platform. The total subset of students excelled in certifications as well as hackerrank platform are $37.05 \%$ for non-IBM students and $80.23 \%$ for IBM students. Furthermore the number of students involved in successful project completion in real time societal problems are $25 \%$ higher in IBM group. The subset of students unaccounted in the hackerrank and programming survey counts are considered to have improved knowledge. Hence the knowledge quantisation is found to be improved by $59.27 \%$ in IBM students. This value will possibly be a non-decreasing value with sound interaction between students, teachers and industry professionals.

\section{Conclusion}

Security \& Cyber Forensics, Internet of Things and Smart City. A study is conducted with a stratified sampling on 400 students of the University in 2 batches, composing students trained through institute-only curriculum and $I^{2}$ curriculum in equal strands. The skills of the students are evaluated through society oriented problems, reflecting the students' ability in applying the engineering knowledge on real world problems. Empirical evaluations are conducted on the outcomes of the students in grounds of internship offers received from industries, papers published and patents filled on societal problems. The evaluations reveal that the design thinking, self-learning ability, state-of-theart knowledge of the $I^{2}$ curriculum-oriented students are $59.27 \%$ ahead from the former case of students, which will definitely help in making the graduates readily employable and aid in societal development. In addition, the collaboration with SAP reveals that the number of students getting placed increases because of possession of international certification. In summary, it is proved that the Institute-Industry collaborations help in making the graduates readily employable and aid in societal development. 


\section{References}

1. Inzelt, Annam $\tilde{A}_{j}$ ria. 2004. The evolution of university - industry - government relationships during transition. Research Policy 33(67): $975-995$

2. Calvert, J, \& P Patel. 2003. University - industry research collaborations in the UK: bibliometric trends. Science and Public Policy 30(2): 85-96

3. University of California. 1989. Guidelines on University-Industry Relations 1989. University of California Office of the President. Retrieved on 29th Dec 2013 from http://www.ucop.edu/ott/ genresources/unindrel.html

4. Bhattacharya, Sujit, \& Arora Praveen. 2007. Industrial linkages in Indian universities: What they reveal and what they imply? Scientometrics 70(2): 277-300

5. Sujit Bhattacharya, Praveen Arora, 2007. Industrial linkages in Indian Universities: What they reveal and what they imply. Scientometrics 70(2): 277-300

6. De'Este, P, \& P Patel. 2007. University - industry linkages in the UK: What are the factors underlying the variety of interactions with industry? Research Policy 36(9): 1295-1313.

7. Annamaria Inzelt, 2004. The evolution of university-industrygovernment relationships during transition. Research Policy 33: 975995

8. Guidelines on University-Industry Relations 1989. University of California Office of the President, www.ucop.edu

9. J. Calvert and P. Patel, 2003. University - Industry Research Collaborations in the UK: bibliometric trends. Science and Public Policy 20(2): 85-96

10. A.N. Parameswaran, E.S.M. Suresh, 2009. A study on the factors promoting Industry-Institute Collaboration for different streams of technical institutions. Paper ID 142, In Proceedings of the 39th ISTE Annual Convention and National Conference on Managing Technical Education for Leveraging Innovation and Entrepreneurship. National Institute of Technology Karnataka, Surathkal

11. Kawday, D., 2019. Industry-Academia Collaboration: Need of the Hour for India. UNIVERSITY NEWS, 57, p.21.

12. https://timesofindia.indiatimes.com/home/education/news/indu stry-academia-linkage-is-only-4-7-out-of-10-in-india-find-out-thereasons/articleshow/71684003.cms

13. https://www.mhrd.gov.in/sites/upload_files/mhrd/files/NEP_Fi nal_English_0.pdf

14. https://www.hackerrank.com/leaderboard?filter=Kalasalingam + University+College \&filter_on=school\&page $=1 \&$ track=python \& typ $\mathrm{e}=$ practice 